Article

\title{
Cooperative Optimization Model of BRT Speed and Timing Based on Dual Station at an Intersection
}

\author{
Peng Zhang ${ }^{1, *}$, Shuangxi Gao ${ }^{1}$, Pengfei Wang ${ }^{1}$ and Wenquan $\mathrm{Li}^{2}$ \\ 1 School of Automobile and Traffic Engineering, Jiangsu University, Zhenjiang 212013, China; \\ 2221904039@stmail.ujs.edu.cn (S.G.); 2221704039@stmail.ujs.edu.cn (P.W.) \\ 2 School of Transportation, Southeast University, Nanjing 210096, China; wenqli@seu.edu.cn \\ * Correspondence: 1000002889@ujs.edu.cn; Tel.: +86-1816-868-7807
}

Received: 7 October 2020; Accepted: 28 October 2020; Published: 2 November 2020

check for updates

\begin{abstract}
This paper presents a binary integer linear programming model based on a dual station at an intersection to make BRT (Bus Rapid Transit) go through the intersection without stopping. This paper first gives the setting of the BRT dual station at the intersection and compares the average BRT delay of the single and dual station at the intersection. Through comparison, it is found that dual station can optimize BRT operations, but there is still room for further optimization. Therefore, this paper establishes a 01 linear programming model based on a dual station. The model takes the shortest travel time of BRT as the optimization objective, and takes the selection of the dual station, green light time of the intersection and cycle time as optimization variables. The case analysis and results show that, compared with the current situation, the average intersection delay of signal priority method, simple dual station method and method proposed in this paper are reduced by $3.51 \mathrm{~s}(8.6 \%)$, $17.27 \mathrm{~s}(42.17 \%)$ and $35.99 \mathrm{~s}(87.89 \%)$; compared with the current situation, the average stopping times at intersection of the signal priority method, simple dual station method and the method proposed in this paper are reduced by $-3(-9.4 \%), 2(6.2 \%)$ and $23(71.8 \%)$, respectively. Under the control of the method proposed in this paper, the average intersection delay is $4.96 \mathrm{~s}$, and the average stopping times at the intersection is 0.18 . This shows that the optimization model proposed in this paper can greatly reduce BRT delay and parking times. The setting of dual station makes the two stations symmetrical to each other, which conforms to the name of the journal. This paper belongs to the field of Symmetry and other scientific disciplines and engineering.
\end{abstract}

Keywords: urban traffic; BRT priority control; speed guidance and signal timing; binary integer linear programming; dual station

\section{Introduction}

Compared with conventional bus, a Bus Rapid Transit (BRT) has independent rights of way. However, compared with rail transit, a BRT is affected by a red light at an intersection, which greatly reduces the competitiveness and attractiveness of BRT in urban traffic [1]. Therefore, reducing the waiting time due to red light and narrowing the gap between BRT and rail transit is an important content of BRT priority control.

Most scholars have studied bus priority in terms of time. Zhou Li [2] carried out active bus priority control through green extension, red light premature break and phase insertion. Li et al. [3] proposed a bus priority signal control method based on pedestrian and pedestrian delays at adjacent intersections. Based on the traffic wave theory, Zhu et al. considers the location of stops at the upstream of the intersection, signal timing, stop time and other factors to establish a bus delay model under the influence of stops for each scene [4]. Xu et al. [5] proposed a novel active signal priority method for arterial BRT on the basis of timed-coordinated signal control. Sun et al. [6] focuses on the optimization 
problem of a signal timing design based on the concept of bus priority. This optimization problem is formulated in the form of a bi-level programming model that minimizes average passenger delay at intersections and vehicle delay in lanes simultaneously.

With the development of cooperative vehicle infrastructure system (CVIS), more and more scholars have introduced speed guidance technology into the study of bus priority. Zheng [7] proposed to use the speed guidance to control the time when the bus arrives at the intersection. This method can use the red-light time to get on and off the passengers and reduce the bus delay. Teng et al. proposed a speed guidance control method based on a dynamic headway deviation threshold, but the implementation effect depends on the organic combination of ITS engineering technology and driver behavior [8]. $\mathrm{Wu}$ et al. presents a novel bus operation control strategy including both holding control and speed control to improve the level of service of transit systems within a connected vehicle environment [9]. Zhang et al. established a road intersection signal control optimization method and model in a vehicle-road collaborative environment on the basis of considering the impact of speed guidance on vehicle operation status, but did not study the interaction process and law between vehicles [10]. Z Wu et al. [11] proposed a coordinated control strategy based on bus signal priority and vehicle speed guidance in a vehicle-road collaborative environment, which improves the punctuality of public transportation, but its departure interval is a specific value and should not be used in practice. Chiara et al. [12] introduced an optimization model that can achieve signal synchronization, real-time bus priority and can provide speed guidance, but it did not consider the management and control of the bus fleet and could not strictly abide by the established timetable.

The above researchers have studied and analyzed bus priority from signal timing and speed guidance, but there are still some deficiencies and defects. The adjustment of signal allocation will cause great interference to social vehicles, and signal priority is difficult to achieve in peak periods.

Zhang Peng et al. [13] proposed a BRT priority control method based on a dual station at an intersection. When the BRT encounters a red light, it can use the red-light time to stop at the upstream station, and when it encounters a green light, it can stop at the downstream station through the intersection. The biggest advantage of this method is that it can reduce the delay and parking times of BRT without affecting the traffic efficiency of social vehicles. However, the method given in this paper is only a simple dual platform control, and there is no collaborative optimization of speed guidance and signal timing.

In order to realize the BRT passing through the intersection without stopping and reduce the interference to social vehicles, this paper establishes a 01 linear programming model based on the dual station intersection, taking the shortest BRT travel time as the optimization objective, and taking the selection of two stations, green light duration and cycle time as variables. Finally, the optimization effect of the model is verified through an example analysis.

\section{The Setting and Delay Analysis of BRT Dual Station}

Generally speaking, a BRT station is set at the entrance or exit of the intersection to facilitate pedestrians to get on and off the bus by using the crosswalk. However, a BRT will be significantly disturbed by the red light at the intersection regarding whether it is set at the entrance or exit. In this paper, a BRT station is set at the entrance and exit of the intersection, as shown in Figure 1.

The delay of BRT single station and dual station is shown in Figure 2. ( $r$ is the red light time, $g$ is the green light time, $C$ is the cycle time, the abscissa length is $r+g$, the ordinate length is $r$ ). It can be seen from the figure that the average delay of single station is

$$
\frac{r^{2}}{2 C}
$$

and the average delay of dual station is

$$
\frac{\left(r-t_{d}\right)^{2}}{2 C}
$$


$t_{d}$ is the time from the completion of boarding and alighting at station A to the end of the red light. Therefore, the setting of dual station can significantly reduce the delay.

From the delay analysis, it can be seen that the setting of dual station can already optimize the current intersection. However, in order to further improve the priority effect of BRT, this paper proposes a collaborative optimization model of speed and signal timing based on dual station at intersection.

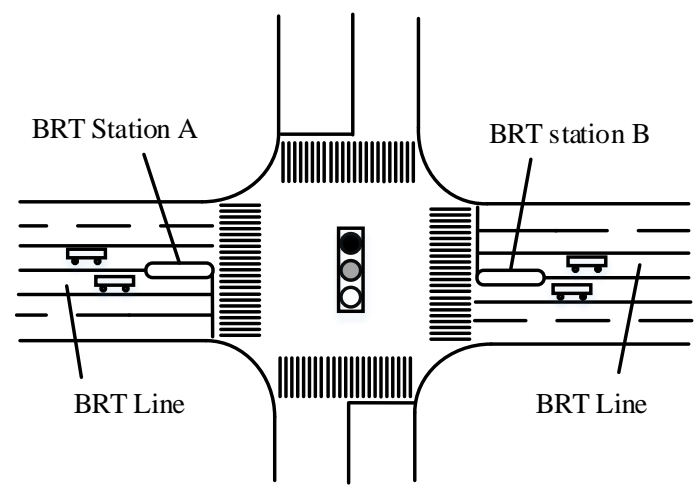

Figure 1. Bus rapid transit (BRT) dual station setup diagram.

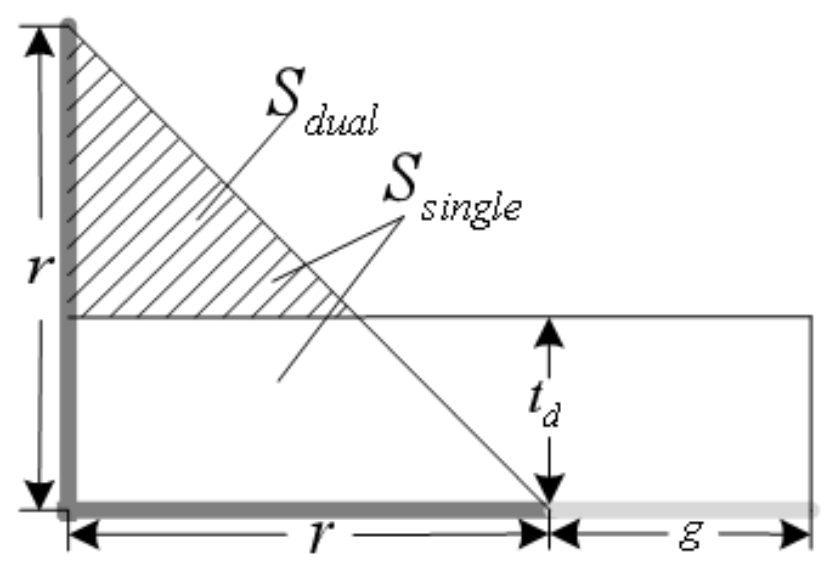

Figure 2. Comparison of red-light delays in a BRT single and dual station.

\section{BRT Priority Collaborative Control Model}

\subsection{Model Assumptions}

(1) The arrival of BRT vehicles is evenly distributed, and the departure time interval is fixed, and only one BRT vehicle arrives in a short time;

(2) All BRT vehicles drive on the BRT lane, the drivers strictly abide by the recommended speed and the speed range of BRT vehicles in each shift is known;

(3) On the premise of not changing the basic signal control phase structure, the signal priority strategy in the model adopts two methods of green light extension and red light early breaking. Other methods (such as phase insertion, phase sequence adjustment, etc.) are not considered for the time being;

(4) BRT vehicle departure time, arrival time and the remaining time of signal timing at the intersections along the way can be predicted.

In the model presented in this paper, the deviation between the actual arrival time and the scheduled arrival time, the current remaining time of intersection and the current running speed of BRT are optimized to reduce the delay of BRT vehicles and the travel time of BRT vehicles. 


\subsection{Constraints}

As shown in Figure $3, t_{0}$ is the departure time of the BRT vehicle; $l_{1}$ is the distance between the departure station and the intersection $S_{1}$; the time when the BRT vehicle arrives at station 1 by speed $v_{1}$ is $t_{11} ; f_{1}$ is the $1 / v_{1}$; after reaching station 1 , the stopping time of the BRT vehicle is $t_{s 1} ; x_{1}$ is a $0-1$ variable. When $x_{1}=0$, the BRT vehicle stops at the exit station; when $x_{1}=1$, the BRT vehicle stops at the entrance station.

$$
t_{11}=t_{0}+l_{1} f_{1}+t_{s} x_{1}
$$

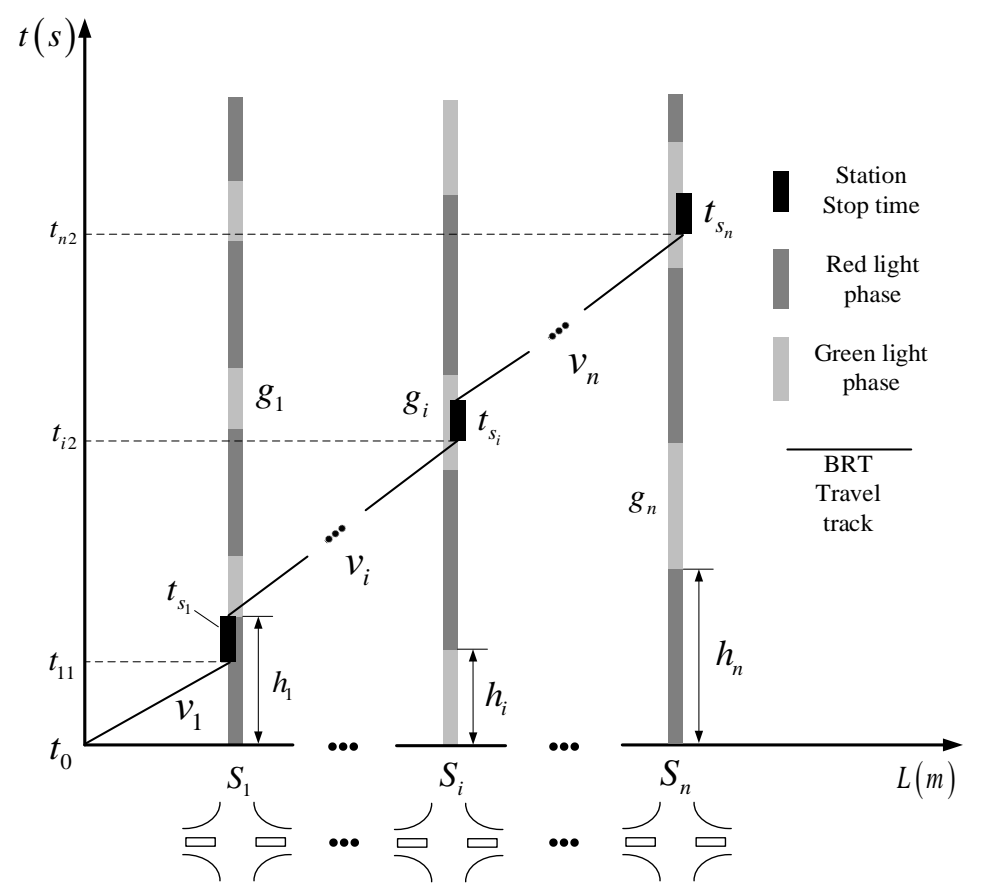

Figure 3. Relationship between BRT vehicle arrival time and intersection phase.

At the intersection $S_{1}$, the time $t_{12}$ when BRT vehicles arrive at station 2 is subject to the following constraints:

$$
\begin{gathered}
t_{12} \geq h_{1}+C_{1} m_{1}+\operatorname{det} g_{1}+m_{1} \operatorname{det} C_{1} \\
t_{12} \leq h_{1}+g_{1}+C_{1} m_{1}+\operatorname{det} g_{1}+m_{1} \operatorname{det} C_{1}
\end{gathered}
$$

where: $h_{1}$ : the remaining time of current signal timing at intersection $S_{1}, h_{1}$ can be both positive and negative; $C_{1}$ : cycle time of intersection $S_{1} ; m_{1}$ : positive integer; $g_{1}$ : green light time of intersection $S_{1}$; $\operatorname{detg}_{1}$ : allowable variation, $\in[-4,4] ; \operatorname{det}_{1}$ : allowable variation, $\in[-10,10]$;

$$
t_{12} \geq t_{11}
$$

At the intersection $S_{1}$, the green time of the signal light is restricted as follows:

$$
t_{g_{\text {min }}} \leq \operatorname{det} g_{1} \leq t_{g_{\max }}, t_{g_{-}} \leq \operatorname{det} g_{1} \leq t_{g_{+}}
$$

At the intersection $S_{1}$, the cycle time of the signal light is restricted as follows:

$$
t_{C_{\min }} \leq \operatorname{det} C_{1} \leq t_{C_{\max }}, t_{C_{-}} \leq \operatorname{det} C_{1} \leq t_{C_{+}} ;
$$

As shown in Figure 3, when the BRT vehicle reaches the entrance station of the $i$ intersection by the speed $v_{i}$, its arrival time is $t_{i 1}$; after BRT vehicles arrive at station $i_{1}$, the station stop time is $t_{s i} ; x_{i}$ is 
0-1 variable, when $x_{i}=0$, BRT vehicles stop at the exit station; when $x_{i}=1$, BRT vehicles stop at the entrance station.

$$
t_{i 1}=t_{i-1,2}+\left(1-x_{i-1}\right) t_{s}+l_{i} f_{i}+t_{s} x_{i}
$$

At the intersection $S_{i}$, the time $t_{i 2}$ when the BRT vehicle arrives at station $i_{2}$ is subject to the following constraints:

$$
\begin{gathered}
t_{i 2} \geq h_{i}+m_{i} C_{i}+\operatorname{det} g_{i}+m_{i} \operatorname{det} C_{i} \\
t_{i 2} \leq h_{i}+g_{i}+m_{i} C_{i}+\operatorname{det} g_{i}+m_{i} \operatorname{det} C_{i}
\end{gathered}
$$

where: $h_{i}$ : the remaining time of the $S_{i}$ current signal timing at the intersection, $h_{i}$ can be both positive and negative; $C_{i}$ : cycle time of intersection $S_{i} ; m_{i}$ : positive integer; $g_{i}$ : green light time of intersection $S_{i}$; In order to avoid the interference of other social vehicles, the adjustment range of green light extension time of the intersection $i$ should be considered when the signal priority control of BRT vehicles is carried out, $\operatorname{det}_{i} \in\left[t_{g_{-}}, t_{g_{+}}\right]$. At the same time, the total cycle time of the intersection should not exceed the upper limit $C_{i t \max }, \operatorname{det} C_{i} \in\left[t_{C_{-}}, t_{C_{+}}\right]$.

$$
t_{i 2} \geq t_{i 1}
$$

At the intersection $S_{i}$, the green time of the signal light is restricted as follows:

$$
t_{g_{\min }} \leq \operatorname{det} g_{i} \leq t_{g_{\max }}, t_{g_{-}} \leq \operatorname{det} g_{i} \leq t_{g_{+}}
$$

At the intersection $S_{i}$, the cycle time of the signal light is restricted as follows:

$$
t_{C_{\text {min }}} \leq \operatorname{det} C_{i} \leq t_{C_{\max }}, t_{C_{-}} \leq \operatorname{det} C_{i} \leq t_{C_{+}}
$$

In summary, the objective function of the model is as follows:

$$
\left\{\begin{array}{c}
\min \quad z=t_{n 2}+\left(1-x_{n}\right) t_{s} \\
\text { subject to }(3-14)
\end{array}\right.
$$

\section{Data Investigation and Collection}

In order to verify the feasibility and effectiveness of the BRT collaborative optimization model, this paper selects five continuous intersections (Tongjiang road of Changzhou BRT line 1 as the research object.

Based on field research, the signal timing of the morning peak (north-south straight) intersection of Changzhou BRT Line 1 and the distance between adjacent intersections are shown in Figure 4 and Table 1.

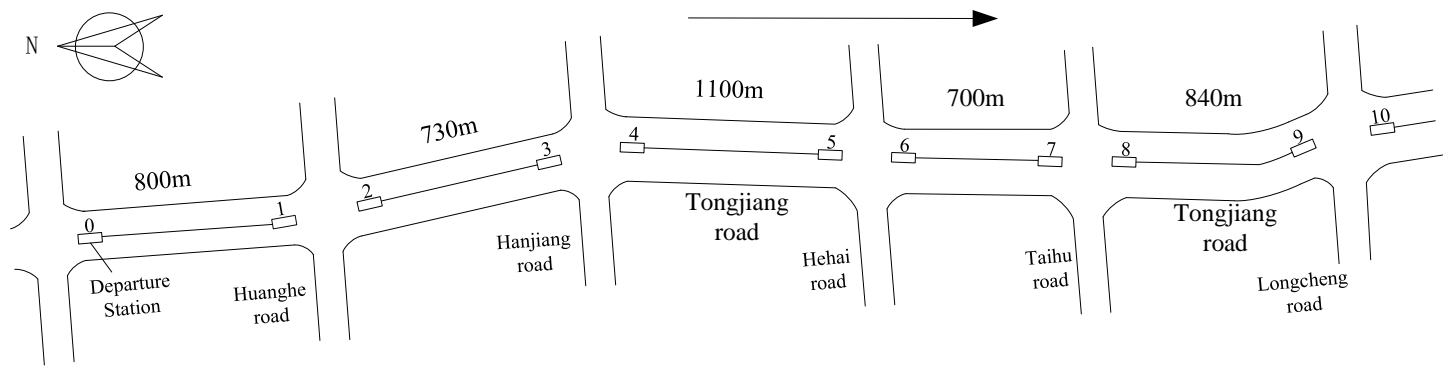

Figure 4. The main road of Tong Jiang Road with a BRT dual station. 
Table 1. Spacing and signal timing of some intersections of Changzhou BRT Line 1.

\begin{tabular}{ccccc}
\hline \multirow{2}{*}{ Intersection Name } & Intersection Spacing (m) & \multicolumn{3}{c}{ Signal Timing } \\
\cline { 3 - 5 } & & Red Light Time (s) & Green Light Time (s) & Cycle Time (s) \\
\hline Tongjiang-Huanghe & 800 & 99 & 47 & 146 \\
Tongjiang-Hanjiang & 730 & 115 & 53 & 168 \\
Tongjiang-Hehai & 1100 & 140 & 74 & 214 \\
Tongjiang-Taihu & 700 & 136 & 98 & 234 \\
Tongjiang-Longcheng & 840 & 161 & 48 & 209 \\
\hline
\end{tabular}

\section{Case Analysis}

Based on field investigation and consultation with BRT drivers, the average speed of a BRT in Tongjiang road is $50 \mathrm{~km} / \mathrm{h}$, the maximum speed is $60 \mathrm{~km} / \mathrm{h}$, the minimum speed is $40 \mathrm{~km} / \mathrm{h}$ and the average stop time of BRT station is $23 \mathrm{~s}$. The BRT departure time $d_{0}=0$, and the departure interval is $5 \mathrm{~min}$. When the first BRT starts, the remaining time $h_{m}$ of current signal timing at each intersection is taken as 0 (the current BRT stops at station 2, 4,6, 8 and 10).

This chapter establishes the optimal BRT station parking plan based on the consideration of BRT speed guidance and signal timing coordination optimization. Binary integer linear programming model is a model with simple solving algorithm and fast solving speed. The branch and bound method is a built-in algorithm of LINGO 12.0 software, which can be used to process a binary integer linear programming model. Therefore, this paper uses LINGO to solve the model. Under four different control methods, the delay and travel time of the ten-shift BRT through five intersections are shown in Table 2.

It can be seen from Figure 5 that the travel time of the BRT under the three control methods has been reduced. Compared with the current situation, the average travel time of signal priority method (average travel time of ten BRT shifts) is reduced by $22.31 \mathrm{~s}(3.6 \%)$, the average travel time of dual station method is reduced by $83.63 \mathrm{~s}(13.50 \%)$ and the average travel time of method proposed in this paper is reduced by $226.89 \mathrm{~s}(36.59 \%)$. Except for BRT of $5 \mathrm{~min}, 10 \mathrm{~min}$ and $20 \mathrm{~min}$, the travel time of the rest departure time in method proposed in this paper is less than $415 \mathrm{~s}$ (the scheduled travel time of BRT vehicles from the departure station to S5).

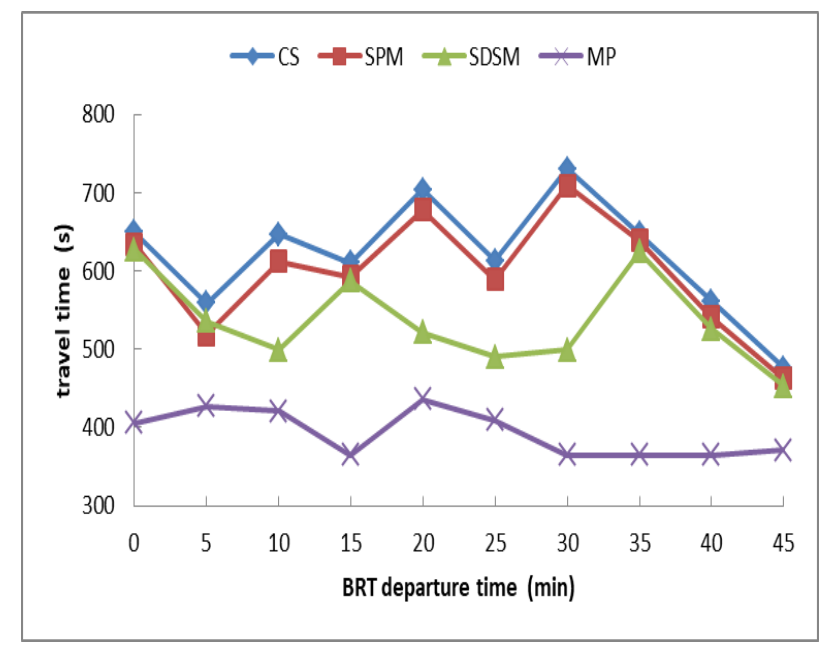

Figure 5. Comparison of delays under different control methods. 
Table 2. BRT travel analysis under different control methods.

\begin{tabular}{|c|c|c|c|c|c|c|c|c|c|c|c|c|c|}
\hline \multirow[b]{2}{*}{ BRT } & \multirow{2}{*}{$\begin{array}{l}\text { Control } \\
\text { Method }\end{array}$} & \multirow{2}{*}{$\begin{array}{c}\text { DT } \\
d_{0}(s)\end{array}$} & \multicolumn{2}{|c|}{$S_{1}$} & \multicolumn{2}{|c|}{$\mathrm{S}_{2}$} & \multicolumn{2}{|c|}{$\mathrm{S}_{3}$} & \multicolumn{2}{|c|}{$\mathrm{S}_{4}$} & \multicolumn{2}{|c|}{$\mathrm{S}_{5}$} & \multirow{2}{*}{$\begin{array}{l}\text { TT } \\
\text { (s) }\end{array}$} \\
\hline & & & $\begin{array}{l}\text { Delay } \\
\text { (s) }\end{array}$ & COP & $\begin{array}{l}\text { Delay } \\
\text { (s) }\end{array}$ & COP & $\begin{array}{l}\text { Delay } \\
\text { (s) }\end{array}$ & COP & $\begin{array}{l}\text { Delay } \\
\text { (s) }\end{array}$ & $\mathrm{COP}$ & $\begin{array}{l}\text { Delay } \\
\text { (s) }\end{array}$ & COP & \\
\hline \multirow{4}{*}{1} & CS & 0 & 88.4 & 0 & 114.44 & 0 & 0 & 0 & 0 & 0 & 31.92 & 0 & 650 \\
\hline & SPM & 0 & 84.4 & 0 & 110.44 & 0 & 0 & 0 & 0 & 0 & 24.64 & 0 & 634.48 \\
\hline & SDSM & 0 & 65.4 & 1 & 0 & 0 & 127.24 & 0 & 19.12 & 0 & 0 & 1 & 627 \\
\hline & MP & 0 & 0 & 0 & 22.2 & 1 & 0 & 0 & 0 & 0 & 0 & 1 & 406 \\
\hline \multirow{4}{*}{2} & CS & 300 & 80.4 & 0 & 0 & 0 & 26.24 & 0 & 0 & 0 & 37.12 & 0 & 559 \\
\hline & SPM & 300 & 76.4 & 0 & 0 & 0 & 13.8 & 0 & 0 & 0 & 13.42 & 0 & 518.62 \\
\hline & SDSM & 300 & 70.84 & 1 & 0 & 0 & 35.8 & 0 & 0 & 1 & 14.12 & 1 & 536 \\
\hline & $\mathrm{MP}$ & 300 & 0 & 0 & 22.2 & 1 & 0 & 0 & 0 & 0 & 0 & 1 & 406 \\
\hline \multirow{4}{*}{3} & CS & 600 & 76.84 & 0 & 0 & 0 & 127.8 & 0 & 26.6 & 0 & 0.52 & 0 & 647 \\
\hline & SPM & 600 & 72.84 & 0 & 0 & 0 & 73.24 & 0 & 19.6 & 0 & 31.32 & 0 & 612 \\
\hline & SDSM & 600 & 49.4 & 1 & 34.44 & 1 & 0 & 0 & 0 & 0 & 0 & 0 & 499.08 \\
\hline & $\mathrm{MP}$ & 600 & 3 & 0 & 21.2 & 0 & 8 & 0 & 15 & 0 & 0 & 1 & 421 \\
\hline \multirow{4}{*}{4} & CS & 900 & 64.4 & 0 & 78.44 & 0 & 5.8 & 0 & 46.6 & 0 & 0 & 0 & 610.48 \\
\hline & SPM & 900 & 60.4 & 0 & 69.44 & 0 & 39.24 & 0 & 0 & 0 & 9 & 0 & 593.08 \\
\hline & SDSM & 900 & 41.4 & 1 & 84.24 & 1 & 0 & 1 & 46.6 & 1 & 0 & 0 & 587.48 \\
\hline & MP & 900 & 0 & 0 & 0 & 0 & 0 & 0 & 0 & 0 & 0 & 0 & 365.2 \\
\hline \multirow{4}{*}{5} & CS & 1200 & 56.4 & 0 & 0 & 0 & 6.24 & 0 & 66.6 & 0 & 159.52 & 0 & 704 \\
\hline & SPM & 1200 & 52.4 & 0 & 0 & 0 & 114.6 & 0 & 37 & 0 & 59.08 & 0 & 678.08 \\
\hline & SDSM & 1200 & 33.4 & 1 & 0 & 0 & 0 & 0 & 43.6 & 1 & 0 & 0 & 521.48 \\
\hline & $\mathrm{MP}$ & 1200 & 39.2 & 0 & 0 & 0 & 0 & 1 & 0 & 0 & 31.6 & 1 & 436 \\
\hline \multirow{4}{*}{6} & CS & 1500 & 48.4 & 0 & 0 & 0 & 0 & 0 & 14.84 & 0 & 134.52 & 0 & 613 \\
\hline & SPM & 1500 & 44.4 & 0 & 15.44 & 0 & 0 & 0 & 83.6 & 0 & 30.56 & 0 & 589 \\
\hline & SDSM & 1500 & 25.4 & 1 & 0 & 1 & 0 & 0 & 37.84 & 0 & 11.52 & 1 & 490 \\
\hline & MP & 1500 & 0 & 0 & 21.2 & 0 & 15 & 0 & 8 & 1 & 0 & 0 & 409.4 \\
\hline \multirow{4}{*}{7} & CS & 1800 & 82.84 & 0 & 0 & 0 & 21.8 & 0 & 126.6 & 0 & 84.52 & 0 & 731 \\
\hline & SPM & 1800 & 78.84 & 0 & 69.88 & 0 & 36.24 & 0 & 109.04 & 0 & 0 & 0 & 709 \\
\hline & SDSM & 1800 & 17.4 & 1 & 42.44 & 1 & 21.8 & 1 & 0 & 0 & 2.12 & 1 & 499 \\
\hline & $\mathrm{MP}$ & 1800 & 0 & 0 & 0 & 0 & 0 & 0 & 0 & 0 & 0 & 0 & 365.2 \\
\hline \multirow{4}{*}{8} & CS & 2100 & 32.4 & 0 & 86.44 & 0 & 113.8 & 0 & 0 & 0 & 0 & 0 & 647.88 \\
\hline & SPM & 2100 & 28.4 & 0 & 0 & 0 & 98.44 & 0 & 0 & 0 & 97.16 & 0 & 639 \\
\hline & SDSM & 2100 & 9.4 & 1 & 86.44 & 1 & 113.8 & 1 & 0 & 0 & 0 & 0 & 624.88 \\
\hline & $\mathrm{MP}$ & 2100 & 0 & 0 & 0 & 0 & 0 & 1 & 0 & 0 & 0 & 1 & 365.2 \\
\hline \multirow{4}{*}{9} & CS & 2400 & 24.4 & 0 & 0 & 0 & 122.24 & 0 & 0 & 0 & 0 & 0 & 561.88 \\
\hline & SPM & 2400 & 20.4 & 0 & 33.44 & 0 & 72.04 & 0 & 0 & 0 & 0 & 0 & 540.88 \\
\hline & SDSM & 2400 & 1.4 & 1 & 0 & 0 & 0 & 0 & 109.36 & 0 & 0 & 1 & 526 \\
\hline & $\mathrm{MP}$ & 2400 & 0 & 0 & 0 & 0 & 0 & 0 & 0 & 0 & 0 & 0 & 365.2 \\
\hline \multirow{4}{*}{10} & CS & 2700 & 22.84 & 0 & 0 & 0 & 37.8 & 0 & 0 & 0 & 0 & 0 & 475.88 \\
\hline & SPM & 2700 & 18.84 & 0 & 12.88 & 0 & 16.16 & 0 & 0 & 0 & 0 & 0 & 462.88 \\
\hline & SDSM & 2700 & 16.4 & 0 & 6.44 & 0 & 14.8 & 1 & 1 & 0 & 1 & 0 & 452.88 \\
\hline & MP & 2700 & 0 & 0 & 0 & 0 & 0 & 0 & 1 & 0 & 1 & 0 & 371 \\
\hline
\end{tabular}

Note: DT = departure time; $\mathrm{COP}=$ choice of station; $\mathrm{CS}=$ current situation; $\mathrm{SPM}$ = signal priority method;

$\mathrm{SDSM}=$ simple dual station method; $\mathrm{MP}=$ method proposed in this paper.

Figure 6 shows the delay time of ten shifts of BRT passing through five intersections under different control methods. It can be seen from Figure 6, compared with the current situation, that the signal priority method, the simple two station method and the method in this paper have optimized and improved the BRT traffic delay. The average intersection delay of the current situation, the signal priority method, the simple two station method and the method in this paper (the average delay of a total of 50 intersections for BRT of ten shifts) is 40.95, 37.44, 23.68 and $4.96 \mathrm{~s}$. Compared with the current situation, the average intersection delay of the signal priority method is reduced by $3.51 \mathrm{~s}$ $(8.6 \%)$, the average intersection delay of the two-station method is reduced by $17.27 \mathrm{~s}(42.17 \%)$, and the average intersection delay of the method in this paper is reduced by $35.99 \mathrm{~s} .(87.89 \%)$. 


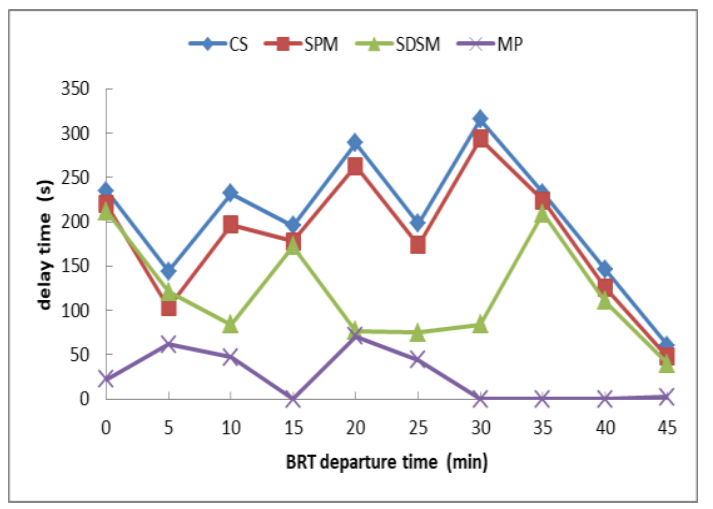

Figure 6. Comparison of travel time under different control methods.

As can be seen from Figure 7, the number of stops (the number of stops caused by red light delay of BRT in 10 shifts, excluding the number of waiting for passage after getting on and off the station at the entrance) for current situation, signal priority method, simple double platform method and this method are 32, 35, 30 and 9, respectively. Compared with the current situation, the number of stops of signal priority method, simple double platform method and this method is reduced by $-3(-9.4 \%), 2(6.2 \%)$ and $23(71.8 \%)$ times, respectively. The average stopping times (the average stopping time of a total of 50 intersections for BRT of ten shifts) of the current situation, signal priority method, double platform method and this method are $0.66,0.7,0.6$ and 0.18 , respectively. Therefore, the proposed model can greatly reduce the number of BRT stops and enhance the stability of BRT.

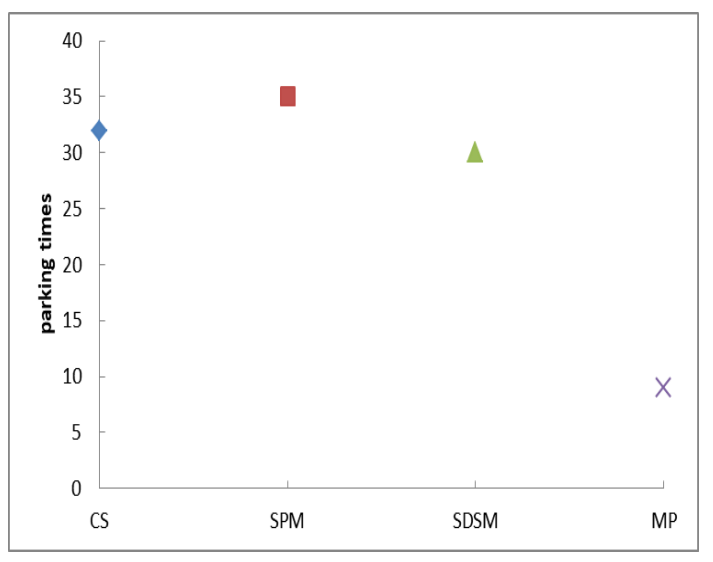

Figure 7. Comparison of parking times control methods.

\section{Conclusions}

(1) Under the condition of no signal timing adjustment and no speed guidance, the setting of BRT dual station can achieve priority control of BRT.

(2) This paper establishes a binary integer linear programming model based on dual stations at intersection, taking the shortest travel time of BRT as the optimization objective, and taking the selection of dual station, green light time of intersection and cycle time as optimization variables. Example calculations show that: the application of this model can greatly reduce BRT driving delays, travel time and the number of stops without disturbing social vehicles.

(3) Previous studies mostly focused on BRT single point priority control. The collaborative optimization model proposed in this paper can realize a BRT trunk line priority and make BRT operation more rapid and stable.

The combination of signal timing and speed guidance can make the bus operation more stable and reduce fuel consumption and emissions. The research of this article still has some shortcomings. 
The research ignores the distance of the intersection itself and the acceleration and deceleration of the BRT when entering and leaving the battle. The model uses the traditional red-light premature interruption and green light extension, but it does not consider the adjustment of the phase sequence and the combination of phases. These issues need further in-depth study.

Author Contributions: Conceptualization, P.Z. and S.G.; methodology, P.Z.; software, P.Z.; validation, S.G., P.W. and W.L.; formal analysis, W.L. and P.W.; investigation, P.W. and W.L.; resources, W.L.; data curation, S.G.; writing—original draft preparation, S.G.; writing—review and editing, S.G.; visualization, S.G.; supervision, P.Z.; project administration, P.Z.; funding acquisition, P.Z. All authors have read and agreed to the published version of the manuscript.

Funding: This research was funded by National Natural Science Foundation of China (71801115) and Natural Science Fund Project of Colleges in Jiangsu Province (13KJB580003) and Initial Research Fund for Highly Specialized Persons of Jiangsu University (12JDG056) and Jiangsu Province Postgraduate Research and Innovation Program (SJCX20_1420).

Conflicts of Interest: The authors declare no conflict of interest.

\section{References}

1. Shah, S.A.R.; Shahzad, M.; Ahmad, N.; Zamad, A.; Hussan, S.; Aslam, M.A.; Khan, A.R.; Asif, M.A.; Shahzadi, G.; Waseem, M. Performance Evaluation of Bus Rapid Transit System: A Comparative Analysis of Alternative Approaches for Energy Efficient Eco-Friendly Public Transport System. Energies 2020, $13,1377$. [CrossRef]

2. Li, Z.; Yi-Zhe, W.; Yang-Dong, L. Study on Signal Priority and Control Method of BRT Based on Vehicle Infrastructure Integration. Traffic Eng. 2017, 12, 60-64.

3. Li, J.; Liu, Y.; Yang, H.; Chen, B. Bus Priority Signal Control Considering Delays of Passengers and Pedestrians of Adjacent Intersections. J. Adv. Transp. 2020, 2020, 3935795. [CrossRef]

4. Zhu, W.-T.; Qian, G.-M. Bus delay model considering influence of stop at upstream of intersection. J. Zhejiang Univ. (Eng. Sci.) 2020, 54, 796-803.

5. Xu, H.-F.; Zheng, Q.-M.; Zhang, K. Signal Priority Technique for Bus Rapid Transit System along an Arterial Based on Vertical Equity. China J. Highw. Transp. 2019, 32, 144-153.

6. Sun, X.; Lin, K.; Jiao, P.; Lu, H. Signal Timing Optimization Model Based on Bus Priority. Information 2020, 11, 325. [CrossRef]

7. Zheng, C.; Zheng, C.-J. Research and Application of Bus Speed Induction. J. Zhengzhou Univ. (Eng. Sci.) 2013, 34, 19-22.

8. Teng, J.; Jin, W.-M. A Section-Speed Guiding Method for Bus Operation Control. J. Tongji Univ. (Nat. Sci.) 2015, 43, 1194-1199.

9. Wu, W.; Ma, W.; Long, K.; Zhou, H.; Zhang, Y. Designing Sustainable Public Transportation: Integrated Optimization of Bus Speed and Holding Time in a Connected Vehicle Environment. Sustainability 2016, 8, 1170. [CrossRef]

10. Zhang, C.B.; Ran, B.; Mei, C.; Zhang, P.L. An Optimization Method of Traffic Signal Control Based on Cooperative Vehicle Infrastructure System. J. Transp. Syst. Eng. Inf. Technol. 2013, 13, 40-45.

11. Wu, Z.; Tan, G.; Shen, J.; Wang, C. A Schedule-based Strategy of transit signal priority and speed guidance in Connected Vehicle environment. In Proceedings of the International Conference on Intelligent Transportation Systems (ITSC), Rio de Janeiro, Brazil, 1-4 November 2016.

12. Colombaroni, C.; Fusco, G.; Isaenko, N. A Simulation-Optimization Method for Signal Synchronization with Bus Priority and Driver Speed Advisory to Connected Vehicles. Transp. Res. Procedia 2020, 45, 890-897. [CrossRef]

13. Zhang, P.; Wang, P.-F.; Sun, C. Research on BRT Priority Control Method Based on Two Stations at Intersection. J. Transp. Syst. Eng. Inf. Technol. 2020, 20, 83-88.

Publisher's Note: MDPI stays neutral with regard to jurisdictional claims in published maps and institutional affiliations. 